\title{
From print to sound in mature readers as a function of reader ability and two forms of orthographic regularity
}

\author{
MILDRED MASON \\ Iowa State University, Ames, Iowa 50011
}

\begin{abstract}
Four experiments using college students as subjects provide evidence that both highly skilled and less skilled mature readers derive the names of printed words from visual access of the lexicon rather than by phonological recoding. Regularity of pronunciation (regular vs. exception words) as a variable of orthographic regularity effective after visual code formation had no effect either between or within reading ability groups. Less skilled readers made more errors and were slower than highly skilled readers on both types of words. Singleletter spatial redundancy, as a variable of orthographic regularity that influences the formation of visual codes, served to differentiate the two groups only in naming nonwords. Highly skilled readers used spatial redundancy to offset the effect of array length, whereas less skilled readers did not. Except for high-frequency words, visual access and retrieval of the pronunciation of words was significantly faster for highly skilled readers. Less skilled readers were most disadvantaged in naming nonwords, a task that requires phonological recoding. Overall results support the hypothesis that reading ability in mature readers is related to the speed of word recognition. Highly skilled readers may make more use of variables of orthographic regularity effective in the formation of visual codes.
\end{abstract}

In order to convert a printed word into its spoken equivalent, a visual code must be formed that includes maintaining the order of the letters within the string. One of the peculiarities of an alphabetic writing system is that the spoken equivalent (the name code) can then be obtained in two very different ways. It can be arrived at by phonological recoding, or it can be retrieved from the internal lexicon following a direct visual access to meaning from the print. Phonological recoding plays a large role in the initial learning-to-read process, enabling the beginning reader to recognize novel printed words if they are part of the spoken vocabulary. It is clear, however, that phonological recoding cannot be the only mechanism used for going from print to sound, even in beginning reading, since it would fail with exception word and with idiographs.

The question being asked in the present investigation is not whether the pronunciation of words is accessed visually or by phonological recoding in mature readers. It is apparent that both mechanisms can be and are used. Indeed, Baron and Strawson (1976, Experiment 2) were able to isolate a group of subjects in a college population who relied heavily on the spelling-to-sound mechanism (the Phoenicians) and another group of subjects who relied heavily on the visual mechanism (the Chinese). The question of interest in the present investigation is

This research was supported by National Institute of Health Grant 1 R01EYO 1813-01. Requests for reprints should be sent to Mildred Mason, Department of Psychology, Iowa State University, Ames, Iowa 50011. which method is most associated with highly skilled reading in mature readers? Given the different data bases for the visual and auditory systems, it would appear that obtaining the pronunciation of a word from its visual representation would be faster than obtaining it via phonological recoding, no matter how abstract the form of the phonological recoding. Therefore, it would seem that reading ability, once it has asymptoted, might be inversely related to the degree of phonological recoding that takes place in going from print to sound. Or, highly skilled college readers may differ from less skilled college readers in terms of the mechanism used to arrive at the sounds of printed words.

\section{EXPERIMENT 1}

The subject variable of reading ability (defined in terms of reading comprehension scores) is used in conjunction with the words used by Baron and Strawson (1976, Experiment 2). These words are dichotomized into a group of exception words and a group of regular words. The exception words necessitate a visual access of the lexicon for naming, because they cannot be phonologically recoded and pronounced by application of spelling-to-sound correspondence rules elaborated by Venezky (1970). Regular words, in contrast, do conform to the rules and they can be named either by going from print to the lexicon or by going from print to sound via phonological recoding. If less skilled readers use phonological recoding for obtaining the names of printed words, they should be greatly disadvantaged 
when required to name words that cannot be correctly named by phonological rules. If highly skilled readers retrieve the names of words from a visual access of the lexicon, it should not make the least bit of difference to them whether words do or do not conform to spelling-to-sound rules. Or, if reading ability in mature readers is related to different mechanisms for going from print to sound, a Reader Ability by Exception vs. Regular Word interaction should be obtained.

The additional variable of interest in Experiment 1 is whether the words are printed in lowercase or in mixed case (alternating lower- and uppercase letters). Since mixing case serves to destroy any overall visual features a word may possess, we would expect highly skilled readers to be more disrupted by mixed case than less skilled readers, if highly skilled readers recognize words as wholes, whereas skilled readers process individual letters.

\section{Method}

Subjects. A pool of potential subjects was developed by administering the Nelson Denny Reading Test, designed for use in Grades 9-16, to some 150 undergraduate psychology students who received course credit for taking the test. Twelve highly skilled and 12 less skilled readers were then selected on the basis of their reading comprehension scores. The highly skilled readers scored in the 90th to 99th percentiles on national norms provided with the test; the less skilled readers scored in the 14 th to 40 th percentiles. In terms of grade-equivalency scores, students scoring below the 8 th grade 7 th month level were eliminated from the potential pool of less skilled readers. All students used as subjects were native English speakers and had been in the top half of their high school class.

The 24 subjects were given the option of course credit or salary for their participation in the experiment.

Stimuli. The $\mathbf{4 0}$ regular words and $\mathbf{4 0}$ exception words used by Baron and Strawson (1976, Table 1, p. 390) were used in the present experiment. A lowercase and a mixed-case version of of each word were typed on Mylar plastic and mounted in slides. As in the Baron and Strawson study, each mixed-case version began with lowercase and then alternated between upper- and lowercase. The words were blocked in groups of 10 by case and by the regular vs. exception variable. The present procedure was identical to that of Baron and Strawson except that the words were presentcd 1 at a time instead of in lists of 10 . This made it possible to measure decoding time unconfounded with duration of articulation time, and to eliminate error latencies from the data analysis. The dependent measure of total time per list of 10 words used by Baron and Strawson includes time needed to say the words, and, of course, includes times for incorrect responses.

Procedure. A directional microphone and a noise-operated Hunter relay indicator, with sensitivity set at the maximum possible, were used in conjunction with a Kodak Carousel slide projector, an Eastman Kodak black glass rear-projection screen, a Lafayette tachistoscopic shutter, a Lafayette digital clock, and Massey-Dickinsen programming modules. The digital clock was activated when the shutter opened to display a slide. Elapsed time was recorded in milliseconds until the subject's initial vocalization, which terminated both the slide display and the clock. Thus, the time needed to decode each word was not confounded with the time needed to fully articulate the word.

In this experiment and in all subsequent experiments, each subject was tested individually by an experimenter who did not know whether the subject was classified as a highly skilled
Table 1

Mean Vocalization Latencies (in Milliseconds) for Regular and Exception Words in Experiment 1 as a Function of Reading Ability and Typecase

\begin{tabular}{|c|c|c|c|c|}
\hline \multirow[b]{3}{*}{ Typecase } & \multicolumn{4}{|c|}{ Word Type } \\
\hline & \multicolumn{2}{|c|}{ Exception } & \multicolumn{2}{|c|}{ Regular } \\
\hline & Mean & ER & Mean & ER \\
\hline & \multicolumn{4}{|c|}{ Highly Skilled Reading Group } \\
\hline $\begin{array}{l}\text { Mixed } \\
\text { Lower } \\
\text { Mixed-Lower Difference }\end{array}$ & $\begin{array}{r}570 \\
520 \\
50\end{array}$ & $\begin{array}{l}.040 \\
.038 \\
.002\end{array}$ & $\begin{array}{r}550 \\
524 \\
26\end{array}$ & $\begin{array}{l}.019 \\
.019 \\
.000\end{array}$ \\
\hline Mixed-Lower Difference & \multicolumn{4}{|c|}{ Less Skilled Reading Group } \\
\hline $\begin{array}{l}\text { Mixed } \\
\text { Lowet } \\
\text { Mixed-Lower Difference }\end{array}$ & $\begin{array}{r}655 \\
583 \\
72\end{array}$ & $\begin{array}{r}.050 \\
.054 \\
-.004\end{array}$ & $\begin{array}{r}639 \\
598 \\
41\end{array}$ & $\begin{array}{l}.050 \\
.027 \\
.023\end{array}$ \\
\hline
\end{tabular}

Note-ER = error rate.

or a less skilled reader. The subjects were told that they would see only words, and they were informed as to case before each block of 10 words. Subjects were also instructed to be as fast and as accurate as possible, and that the word would disappear from the screen with their initial vocalizations.

Following practice trials with lowercase and mixed-case words, each subject went through 160 trials arranged in two slide trays, with repeats of words by case separated by slide trays. As in the Baron and Strawson (1976) study, two presentation orders were used.

\section{Results and Discussion}

Errors. The overall error rates were .029 for the highly skilled readers and .045 for the less skilled readers. Self-corrections were treated as errors, but were recorded. The highly skilled readers spontaneously corrected $26 \%$ of their errors; the less skilled readers spontaneously corrected $17 \%$ of their errors. The analysis of variance performed on the error data shown in Table 1 showed a significant main effect of reader ability $[F(1,22)=5.827, p<.025]$.

Both groups of readers made significantly more errors on the exception words than on the regular words $[F(1,22)=10.668, p<.005]$. This was due, however, to 27 mispronunciation errors (sounding out the "w") on the one exception word "sword." The generality of the higher error rate on exception words is brought into question by the fact that errors were made on 19 of the 40 regular words and 15 of the 40 exception words. As Baron and Strawson (1976) point out, exception words may differ from regular words not only in terms of conformity to spelling-to-sound rules, but also in the extent to which they are archaic, have highly specialized meanings, and are borrowings from other languages. The higher error rate on exception words is probably due to these factors for a few words rather than to the failure of exception words in general to follow letter-to-sound correspondence rules.

The highly skilled readers' error rates did not vary as a function of whether the words were presented in mixed-casi font or in lowercase font. The effect of 
alternating case was, however, significant for the less skilled readers, with the effect being limited to the regular words $[F(1,22)=14.393, p<.001]$. The less skilled readers had particular difficulty with the regular word "toll" presented in mixed case, with 8 of the 12 less skilled readers reading "tOlL" as "toil." Only two of the 12 highly skilled readers made that error.

Since alternating case affects the overall visual configuration of a word, it is of some interest that the highly skilled readers were not affected (in terms of errors) by mixing case. The hypothesis that highly skilled readers may be faster at word decoding because they recognize words as wholes, whereas less skilled readers do not, would predict that alternating case would cause the skilled readers to make more errors and would also serve to slow them down vis-a-vis the less skilled readers. In point of fact, just the opposite seems to be true: It is the less skilled readers who are most disadvantaged with mixed case as far as errors are concerned. Groff (1975) found that only $20 \%$ of a sample of high-frequency words found in school book sources can be represented by a unique shape and concluded that the shape of a word would not be a useful cue for accurate word recognition. Conceivably, the less skilled readers do use shape, in which case their significantly higher error rates would simply lend credence to Groff's conclusion that shape is a poor cue for accurate word recognition.

The strongest proponent of the hypothesis that words are recognized by superletter features is F. Smith (1971). The present data would seem to refute the hypothesis for at least the highly skilled readers. As E. E. Smith and Spoehr (1974) point out, the most damaging evidence against the hypothesis that discriminating visual features are developed for entire words is that it cannot predict the perceptual advantage enjoyed by well structured but entirely novel pseudowords (e.g., Baron \& Thurston, 1973).

Vocalization latencies. A mean reaction time (RT) for correct responses was calculated for the four conditions for each subject. A mixed-ciesign analysis of variance was performed on the data shown in Table 1, with reading ability as a between-subjects variable. Word class (regular or exception) and case (lowercase or mixed) were within-subjects factors. There was a significant overall effect of reading ability $[F(1,22)=7.684$, $\mathrm{p}<.025$ ], indicating that the less skilled readers took longer to name both types of words than did the highly skilled readers. Thus, the time needed to go from print to sound with words differentiates skilled and less skilled comprehenders, even at the college level.

Reading ability did not interact with the other variables manipulated. Less skilled readers simply seem to make more errors and to take longer to read both regular and exception words aloud than do highly skilled readers. The effect of the exception vs. regular word variable was negligible for both groups of readers
$[F(1,22)<1]$. Since the orthographic variable of regularity of pronunciation made no difference either within or across reading ability groups, it seems reasonable to conclude that neither group of readers go from print to sound with words via phonological recoding.

The only significant effect in addition to reading ability was the effect of case $[F(1,22)=54.00$, $\mathrm{p}<.0001]$, which indicated that word naming required more time with mixed-case than with lowercase presentations. As can be seen from Table 1, the effects of case were, if anything, greater for the less skilled readers than for the highly skilled readers, although the trend was not significant. Thus, there is no evidence from either errors or RTs that highly skilled readers recognize words as wholes, whereas less skilled readers do not. There is, however, the distinct possibility that highly skilled readers differ from less skilled readers in that they recognize letters on a more abstract level and are less influenced by the physical form of a letter. An analogy with chess pieces may be appropriate: It does not matter what the particular pieces look like, as long as they can be differentiated and their rules are known. With letters, the "rule" would be the phoneme. It should be pointed out that mixing case disrupts preliminary letter identification, as well as overall visual form (McClelland, 1976).

In order to determine if the failure to find any effect of the regular vs. exception word variable for either reading group could be due to the fact that error RTs were not included in the analysis (as they were in the Baron \& Strawson, 1976, study), the data were reanalyzed using all RTs. The results were substantially the same as in the analysis of correct responses only: It takes no longer to go from print to sound with "sword" than it does with "swoop," even when error responses are included.

Since the less skilled readers made significantly more errors than did the highly skilled readers, one might question the propriety of an analysis of variance based on a disparate number of correct observations. Therefore, the data for correct responses were reanalyzed separately for each group. Only a significant effect of case emerged $[F(1,11)=17.00, p<.005$, for the highly skilled readers; $F(1,11)=38.00, p<.0001$, for the less skilled readers]. In neither analysis was there a suggestion of an effect of regular vs. exception words.

\section{EXPERIMENT 2}

The results of the first experiment were that less skilled readers made more errors and were slower than highly skilled readers in naming both regular and exception words. A natural question at this point is whether the observed differences were due to the visual and/or name code-formation components of the vocalization latency task, or to the motor-articulatory components of the task. If less skilled readers are simply slower in producing the name, the obtained results would not be 
germane to the silent reading process. If, however, the obtained differences in Experiment 1 cannot be attributed to the motor components of the naming task, it would suggest that less skilled readers require more time to get to the meanings of words. The failure to find any relationship between reading ability and the orthographic variable of regularity of pronunciation represented by the regular vs. exception word dichotomy would suggest that both groups of readers go directly from print to meaning and retrieve the pronunciation of words from the internal lexicon. It should be pointed out that regularity of pronunciation is not an orthographic variable that would be expected to affect visual code formation. Spelling-to-sound correspondence rules would come into play subsequent to letter recognition. The failure in Experiment 1 to find the anticipated interaction of reading ability with the regular vs. exception word variable would point to reader ability differences in the visual components of word recognition. Before it can be concluded that this is indeed the case, however, it will be necessary to rule out the motor components of the vocalization latency task as a possible locus of the obtained differences.

The naming control paradigm used by Forster and Chambers (1973) is used in Experiment 2 in conjunction with the regular and exception words used in the first experiment. Half of the subjects in each reading ability group are shown each word for $2 \mathrm{sec}$ and are instructed to say the word aloud as quickly as possible in response to a light that appears on the screen after the word has been in view for $2 \mathrm{sec}$. The other half of the subjects constitute a partial replication of Experiment 1 . If the observed differences in Experiment 1 were due to the fact that less skilled readers are slow in initiating the vocal response, similar differences should be obtained even when abundant time is allowed for word recognition and retrieval of the pronunciation from the lexicon. An additional advantage of having the naming control condition is that it permits an assessment of possible time differences in initial sound formations between the particular regular and exception words used by Baron and Strawson (1976). It is possible that the initial sounds of the exception words, due to voicing and phonemic structure, might have triggered the voice relay more rapidly than did the regular words. Thus, the apparent equality of regular and exception words found in Experiment 1 could be an artifact.

\section{Method}

Subjects. Following administration of the Nelson Denny Reading Test to a large pool of potential subjects, 24 highly skilled and 24 less skilled readers were selected to serve as subjects by the criteria used in Experiment 1 . Half of the subjects in each reading ability group were randomly assigned to the naming control condition; the other half served in a replication of the lowercase condition used in Experiment 1.

The 48 subjects were given the option of course credit or salary for their participation in the experiment.

Stimuli. The lowercase regular and exception words of Experiment 1 served as the stimuli in Experiment 2. In order to test the generality of the results in Experiment 1, and to insure that they were not due to the particular order of words used within each 10-word group, the words were rearranged to form different lists from those used in Experiment 1.

Procedure. The apparatus was identical to that used in Experiment 1. Following practice trials with lowercase regular and exception words, each subject went through two blocks of trials. Half of the subjects started with regular words, the other half with exception words. For the 24 subjects in the naming control condition, the word stayed on the screen for 2 sec and the subjects were instructed to say the word aloud as quickly as possible when a light appeared on the screen below the word. The digital clock was activated by the light and was terminated by the subject's initial vocalization. The 24 subjects in the regular vocalization latency condition were instructed to say the word aloud as quickly as possible after it appeared on the screen, and the time from onset of the word to initial vocalization was recorded in milliseconds.

\section{Results and Discussion}

The mean vocalization latencies shown in Table 2 for the naming control condition make it clear that the reader ability differences obtained in Experiment 1 cannot be attributed to the motor-articulatory components of the vocalization latency task. When words remained in view for $2 \mathrm{sec}$ prior to the appearance of a light that served as the signal to pronounce the word, all reader ability differences vanished. As can also be seen from the naming control condition in Table 2, regular and exception words did not differ in terms of time needed to trigger the voice-relay key.

The results of Experiment 1 were replicated in the vocalization latency condition of Experiment 2. The analysis of variance performed on the vocalization latency data shown in Table 2 revealed only a significant main effect of reader ability $[F(1,22)=8.02, p<.01]$. Neither the main effect of the regular vs. exception word variable nor its interaction with reader ability resulted in any appreciable variability $[\mathrm{F}(1,22)<1$ for both factors].

The possibly attractive hypothesis that reading ability might be related to the Chinese vs. Phoenician subject variable identified by Baron and Strawson (1976) turns out to be untenable in terms of mechanisms used to go from print to sound with single words. In two

Table 2

Mean Vocalization Latencies (in Milliseconds) for Regular and Exception Words in Experiment 2 as a Function of Reading Ability and Condition

\begin{tabular}{lccccc}
\hline & \multicolumn{4}{c}{ Word Type } \\
\cline { 2 - 3 } \multicolumn{1}{c}{ Condition } & \multicolumn{2}{c}{ Exception } & & \multicolumn{2}{c}{ Regular } \\
\cline { 2 - 3 } \cline { 5 - 6 } & Mean & ER & & Mean & ER \\
Vocalization Latency & 505 & .038 & 510 & .019 \\
Naming Control & 330 & .010 & 333 & .000 \\
& \multicolumn{4}{c}{ Less Skilled Reading Group } \\
Vocalization Latency & 576 & .077 & 578 & .036 \\
Naming Control & 335 & .023 & 335 & .010 \\
\hline
\end{tabular}

Note-ER = error rate. 
experiments comparing words that can only be pronounced by visual access with words that can be named by either mechanism, there is no suggestion that highly skilled and less skilled readers differ in terms of which mechanism they use. If, as hypothesized, less skilled adult reading can be characterized by a greater degree of phonological recoding in going from print to sound, the less skilled readers should have been particularly disadvantaged with the exception words. Instead, it would appear that there are major differences in the way highly skilled and less skilled readers gain visual access to the lexicon for retrieving the sounds of words. The typefont manipulation of Experiment 1 argues against the hypothesis that the superior performance of the highly skilled readers can be attributed to their recognizing words as wholes. It would also appear that orthographic regularity defined in terms of regularity of pronunciation is not particularly important in adult word recognition and decoding, since it does not differentiate highly skilled and less skilled adult readers. Since letters must be recognized before they can be mapped onto sounds, the form of orthographic regularity manipulated in Experiments 1 and 2 would not be expected to facilitate the formation of a visual code. This also points to the importance of the visual components of word recognition in the word-naming task and serves to focus attention on other forms of orthographic regularity present in words that can affect the rate at which letters are recognized.

\section{EXPERIMENT 3}

Whereas words can be named either by phonological recoding or by going directly from print to meaning and retrieving the pronunciation from the lexicon, nonwords, since they have no lexical representation, must be converted from print to sound via the process of phonological recoding. Following the arguments set forth by Coltheart (in press), I will assume that phonological recoding is done by parsing the visual string into letters that correspond to phonemes and assigning phonemes to the units. By comparing the effects of variables such as number of letters on vocalization latencies for nonwords with those obtained for words, inferences can be made about the processes involved in word naming. Thus, by including nonwords in the vocalization latency task, we have a converging operation for testing the hypothesis that highly skilled and less skilled mature readers differ in terms of the mechanism used to name words. If words are converted from print to sound by phonological recoding, vocalization latencies for words should be similarly affected by variables that affect nonword vocalization latencies. This would not be the case if the pronunciation of words is obtained from the lexicon. This question, of course, is related to the question of how the meaning of isolated words is assessed. If the pronunciation of a word is retrieved from the lexicon, then the meaning is accessed visually. Coltheart (in press) presents evidence that lexical decisions about words are always made visually. However, this is somewhat more complicated than the question at hand, which is simply whether words and nonwords are named the same way by both highly skilled and less skilled college readers. Forster and Chambers (1973) found that words are not named the same way nonwords are named, but, rather, that the pronunciation of words is retrieved from the lexicon. On the other hand, Frederiksen and Kroll (1976) found that words and nonwords were converted from print to sound in very much the same fashion, including the same slope effect for each additional letter added to the display and no syllable effects for either words or nonwords. In the Frederiksen and Kroll study, however, both words and nonwords were presented for only $50 \mathrm{msec}$, and error rates were high. The interpretation of latencies obtained with this procedure of briefly presented displays is not straightforward (see Pachella, 1974). In the present experiment, the display remains in view until the initial vocalization is produced. Of particular interest in Experiment 3 is whether the subject variable of reading ability will interact with the word vs. nonword variable.

In addition to the variables of lexicality (words vs. nonwords) and string length, Experiment 3 includes single-letter spatial redundancy as a variable of orthographic regularity that has been shown to influence the formation of visual codes (Mason, in press; Massaro, Venezky, \& Taylor, in press; McClelland, 1976, Experiment 1; McClelland \& Johnston, 1977).

Single-letter spatial redundancy is a specific variable involved in orthographic regularity that has only recently been subjected to experimental investigation. This form of orthographic regularity stems from the fact that there is considerable constraint in printed English words as to which specific letters may occur in which serial positions. For example, given the population of six-letter words sampled by Mayzner and Tresselt (1965), the letter " $y$ " has a very high probability of occurring in the sixth serial position and a very low probability of occurring in the first serial position; the letters " $b$ " and " $p$ " occur with high probability in the first serial position and are highly improbable in the sixth. Massaro et al. (in press) covaried single-letter spatial redundancy and linguistically defined permissible letter sequences and found both variables to be operative in the visual resolution of letters. The effect of spatial redundancy was of somewhat greater magnitude than the effect of permissible letter sequences. McClelland (1976, Experiment 1) found that letters occurring in highly probable serial positions in unrelated letter strings had a reliable advantage over letters occurring in improbable serial positions in unrelated strings. McClelland and Johnston (1977) found that singleletter spatial redundancy was highly correlated with 
accuracy of report, whereas bigram redundancy was not. Spatial redundancy may operate at the featureextraction stage by creating a distance metric between letters that share common visual features. Mason (in press) manipulated spatial redundancy and visual confusability with symbols. Constraint per se (reducing the number of valid alternatives at each serial position) was not enough to facilitate performance. It was only when the constraint served either to keep confusable symbols out of the same string or to maximize the distance between them within the string that facilitation was obtained.

More germane to the present investigation, however, are two earlier studies that investigated spatial redun. dancy in conjunction with reading ability in six th-grade children. Mason (1975) found that good and poor sixthgrade readers could be differentiated at the level of single-letter identification in a yes-no RT task by their ability to use spatial redundancy. The children had to determine the presence or absence of a target letter in six-letter strings that were either words or nonwords. Two nonword anagrams were constructed for each word used by permuting the letters within the word in accordance with the Mayzner and Tresselt (1965) single-letter serial position frequency counts for sixletter words. One nonword anagram possessed the maximum spatial redundancy possible, which was always greater than that of the word. The second nonword anagram possessed the least amount of spatial redundancy possible. Thus, the qualitative word vs. nonword distinction was changed to a quantitative spatial redundancy dimension. Good and poor sixth-grade readers were equivalent in single-letter identification only on the low spatial redundancy strings. The good readers' performance on the nonwords with high spatial redundancy showed that word membership was neither a necessary nor a sufficient condition for facilitation in the letter-identification task. A second study (Mason \& Katz, 1976) extended the finding to nonlinguistic stimuli, with good sixth-grade readers being superior to poor sixth-grade readers only when spatial redundancy was built into the set of unfamiliar symbols used as stimuli. The importance of these two studies is that they indicate that the processes involved in the component skill of single-letter identification are not irrelevant to the reading process.

If highly skilled and less skilled mature readers differ primarily in visual code formation rather than in the mechanism used to derive the names of words, an interaction of reading ability and spatial redundancy should be obtained in Experiment 3.

\section{Method}

Subjects. Ten highly skilled and 10 less skilled readers were selected on the basis of comprehension scores on the Nelson Denny Reading Test, which was administered to intact freshman English classes during instructional periods. ${ }^{2}$ Selection criteria were the same used in the previous experiments, with students scoring below the 14th percentile excluded from the pool of potential less skilled readers. The data from one less skilled reader was eliminated from the data analysis. This subject either did not understand the experimental task or else found it extremely difficult, producing latencies that were twice as long as the next slowest less skilled reader. All subjects received salary for their participation in the experiment.

Stimuli. A complete list of the 160 word and nonword stimuli are given in Table 3 . The 160 stimulus strings used

Table 3

Words and Nonwords Used in Experiment 3

\begin{tabular}{|c|c|c|c|c|c|c|c|c|}
\hline & \multicolumn{4}{|c|}{ High Spatial Redundancy } & \multicolumn{4}{|c|}{ Low Spatial Redundancy } \\
\hline & \multicolumn{2}{|c|}{ Four Letters } & \multicolumn{2}{|c|}{ Six Letters } & \multicolumn{2}{|c|}{ Four Letters } & \multicolumn{2}{|c|}{ Six Letters } \\
\hline & Words & Nonwords & Words & Nonwords & Words & Nonwords & Words & Nonwords \\
\hline & card & cird & basket & bosket & also & ilso & action & abtion \\
\hline & cold & facy & behind & borind & army & ormy & bishop & bushop \\
\hline & $\operatorname{corn}$ & marn & coming & caming & aunt & eunt & branch & brench \\
\hline & dark & dirk & compel & camted & blow & blaw & breath & broath \\
\hline & face & foce & during & cering & camp & cemp & custom & cistom \\
\hline & fact & falk & fairly & faitly & club & clab & detail & dutail \\
\hline & game & gace & family & fomily & drag & drig & editor & edator \\
\hline & hard & hord & famous & fories & draw & drow & employ & emcloy \\
\hline & hold & hald & firmly & farmly & echo & icho & enough & inough \\
\hline & join & jain & forest & farist & evil & avil & growth & griwth \\
\hline & lack & parn & market & pamket & flag & flug & income & insome \\
\hline & love & tove & parent & porunt & hero & haro & inform & inferm \\
\hline & nice & nole & partly & parmly & idea & udea & insect & ensoct \\
\hline & part & mard & period & poried & inch & ench & itself & itpelf \\
\hline & pine & poce & pocket & porket & iron & aron & length & lingth \\
\hline & race & rale & remind & pomund & know & knaw & obtain & octain \\
\hline & rule & ruce & should & sheild & news & nuws & orange & oringe \\
\hline & safe & sace & spring & shrung & obey & abey & prison & prasin \\
\hline & time & tice & string & shring & swim & swom & public & pebloc \\
\hline & yard & tald & worthy & wertly & upon & ipon & wisdom & wesdom \\
\hline MSR & 2229 & 2304 & 1403 & 1533 & 1025 & 1002 & 746 & 746 \\
\hline SD & 414 & 511 & 217 & 269 & 344 & 361 & 139 & 119 \\
\hline
\end{tabular}


represented a factorial combination of words and nonwords, four and six letters, and high and low spatial redundancy. To insure that all words were known to both reading ability groups, 80 words with no repeats of letters were selected that were rated high in frequency by the Thorndike and Lorge (1944) word count. Single-letter spatial redundancy was calculated by summing over serial positions with the Mayzner and Tresselt (1965) single-letter frequency counts for four- and six-letter words. As can be seen from the mean single-letter spatial redundancy counts shown in Table 3, there was a clear separation within each word length along the dimension of spatial redundancy, with words equated for frequency of occurrence both within and across word lengths. However, the four-letter words were higher in spatial redundancy than were the sixletter words. This could not be prevented, given the different type-token distributions for four- and six-letter words. It should also be noted that spatial redundancy is confounded with number of syllables in the four-letter condition, but not in the six-letter condition. This confounding of spatial redundancy and number of syllables in the four-letter condition was not considered at the time to be important, since Fredericksen and Kroll (1976) had found no effect of number of syllables on naming times for either words or nonwords.

Each of the four sets of 20 words was permuted to form pronounceable nonwords with comparable single-letter spatial redundancy. The same distribution of letters and overall consonant-vowel patterns present in each set of words were maintained in the permuted nonwords. Each stimulus was typed in lowercase on Mylar plastic and prepared for slide mounts. The six-letter stimuli were centered. To control for the possible effects of retinal location, half of the four-letter stimuli were placed to the left, with the first letter corresponding to the position of the first letter of the six-letter stimuli; the other half were to the right, with the fourth letter corresponding to the position of the sixth letter of the six-letter stimuli.

The 160 stimuli were quasirandomly arranged in two trays, with the constraint that the members of any one word-nonword pair shown in Table 3 not be in the same tray. Each tray constituted 10 replications of the eight basic conditions and was counterbalanced for words and nonwords, number of letters, and the two levels of spatial redundancy. Two orders of tray presentations were used, with half of the subjects in each reading ability group receiving each order.

Procedure. The apparatus and procedure used in Experiment 1 were used, with the exception that subjects were instructed that they would see both words and nonwords, which they were to say aloud as rapidly as possible. Following a series of practice trials with words and nonwords, each subject went through two blocks of 80 trials each.

\section{Results and Discussion}

Vocalization latencies. A mean RT was determined for each subject in each of the eight conditions. A mixed-design analysis of variance was performed on the group means shown in Table 4, with reading ability as a between-subjects factor. Lexicality (words or nonwords), array length (four or six letters), and spatial redundancy (high or low) were within-subjects factors. ${ }^{3}$

Although the highly skilled readers' overall mean was $106 \mathrm{msec}$ faster than the less skilled readers' mean, reading ability as a main effect did not reach significance $[F(1,17)=3.76, p<.07]$. Reading ability did, however, significantly interact with the other variables of interest.

Nonwords took longer to name than did words $[F(1,17)=62.30, p<.0001]$. The effect of lexicality, however, was significantly greater for the less skilled
Table 4

Mean Vocalization Latencies (in Milliseconds) for Words and

Nonwords in Experiment 3 as a Function of Reading Ability, Spatial Redundancy, and Array Length

\begin{tabular}{|c|c|c|c|c|c|c|}
\hline \multirow{2}{*}{$\begin{array}{l}\text { Spatial } \\
\text { Redun- } \\
\text { dancy }\end{array}$} & \multicolumn{3}{|c|}{ Words } & \multicolumn{3}{|c|}{ Nonwords } \\
\hline & $\begin{array}{l}\text { Four } \\
\text { Letters }\end{array}$ & $\begin{array}{c}\text { Six } \\
\text { Letters }\end{array}$ & Mean & $\begin{array}{c}\text { Four } \\
\text { Letters }\end{array}$ & $\begin{array}{c}\text { Six } \\
\text { Letters }\end{array}$ & Mean \\
\hline & \multicolumn{6}{|c|}{ Highly Skilled Reading Group } \\
\hline $\begin{array}{l}\text { High } \\
\text { Low }\end{array}$ & $\begin{array}{l}615 \\
625\end{array}$ & $\begin{array}{l}652 \\
639\end{array}$ & $\begin{array}{l}633 \\
632\end{array}$ & $\begin{array}{l}674 \\
750\end{array}$ & $\begin{array}{l}755 \\
804\end{array}$ & $\begin{array}{l}714 \\
777\end{array}$ \\
\hline \multirow[t]{2}{*}{ Mean } & 620 & 645 & 632 & 712 & 779 & 745 \\
\hline & \multicolumn{6}{|c|}{ Less Skilled Reading Group } \\
\hline $\begin{array}{l}\text { High } \\
\text { Low }\end{array}$ & $\begin{array}{l}654 \\
672\end{array}$ & $\begin{array}{l}732 \\
699\end{array}$ & $\begin{array}{l}693 \\
685\end{array}$ & $\begin{array}{l}762 \\
894\end{array}$ & $\begin{array}{l}970 \\
975\end{array}$ & $\begin{array}{l}866 \\
934\end{array}$ \\
\hline Mean & 663 & 715 & 689 & 828 & 972 & 900 \\
\hline
\end{tabular}

readers than for the highly skilled readers $[F(1,17)=5.80$, $p<.03]$. Thus, the largest reading ability differences were on the nonwords, which, since they have no representation in long-term memory, preclude the possibility of lexical access with retrieval of the pronunciation. The obtained interaction is in the opposite direction from what would be predicted if less skilled readers normally go from print to sound via phonological recoding. It is in naming nonwords, which requires phonological recoding, that less skilled readers are most disadvantaged in comparison to the highly skilled readers. Similar interactions of lexicality and reading ability have been found in children (Golinkoff \& Roskinski, 1976; Perfetti \& Hogaboam, 1975) and in high school students (Frederiksen, Note 1). It may be that the nonword decoding task successfully differentiates skilled and less skilled reading at all age levels because it provides a measure of linguistic awareness, which would include the ability to internalize and generalize the rules of English phonology. Mattingly (1972) makes the point that learning to read an alphabetic writing system is a secondary form of linguistic activity that relies critically upon the reader's awareness of the primary linguistic activities of speaking and listening. The increased abstractness of alphabetic writing systems may well necessitate a fairly high degree of linguistic awareness. There is evidence to support the notion that reading disability is more prevalent with an alphabetic writing system than it is with nonalphabetic writing systems (Makita, 1968; Rozin \& Gleitman, 1977; Rozin, Poritsky, \& Sotsby, 1971). Leaving aside for the moment the question of whether highly skilled and less skilled readers differ in the way they go from print to sound with words, it would appear that, if the names of words were obtained only via phonological recoding, less skilled readers would be more disadvantaged than highly skilled readers.

Six-letter strings took significantly longer to decode than did four-letter strings $[\mathrm{F}(1,17)=58.16, \mathrm{p}<.0001]$. This effect of array length, however, was greater for the 
less skilled readers than it was for the highly skilled readers $[F(1,17)=7.88, p<.01]$. Adding two letters resulted in an average increase of $99 \mathrm{msec}$ for the less skilled readers, more than twice the average increase of $46 \mathrm{msec}$ for the highly skilled readers. In addition, the effect of adding two letters to the array was greater for nonwords than it was for words $[F(1,17)=34.01$, $\mathrm{p}<.0001$ ], with the average increase being $38 \mathrm{msec}$ for words and $104 \mathrm{msec}$ for nonwords. Since the effect of adding two letters was different for words and nonwords, it would appear that neither group of readers go from print to sound with words the same way they do with nonwords. Since nonwords must be named via phonological recoding, this is tantamount to saying that words are not named by phonological recoding by either group of readers. The present finding of an Array Length by Lexicality interaction is in conflict with the finding of an overall increase of approximately $28 \mathrm{msec}$ for each additional letter in both word and nonword arrays by Frederiksen and Kroll (1976). This apparent conflict could be due to the fact that words used in their study were drawn from four classes of word frequency. As Frederiksen and Kroll point out, lowfrequency words that are not known to the subjects are effectively nonwords. Thus, judging from their reported error rates, the larger effect of array length on words that Frederiksen and Kroll obtained might be due, in part at least, to the fact that a high percentage of the words they used were effectively nonwords rather than words. It is also possible that the larger effects of lexicality and the interaction of array length with lexicality found in the present study are due to: (1) the reading ability subject variable-both highly skilled and less skilled readers may use a direct lexical access for naming words, albeit probably for different reasons, or (2) procedural differences between the two studies, since displays remained in view for only $50 \mathrm{msec}$ in the Frederiksen and Kroll study.

As was to be expected from the two-way interactions, there was a significant Reading Ability by Lexicality by Array Length interaction $[F(1,17)=5.01, p<.04]$. Simple-effects tests were performed on the means shown in Figure 1. The effect of adding two letters to word arrays was significant for the less skilled readers $[F(1,17)=22.50, p<.001]$, but not for the highly skilled readers $[F(1,17)=3.00$, n.s. $]$. Ability interacted with array length on the nonword displays $[F(1,17)=14.50, p<.005]$, but not on the word displays $[F(1,17)=1.50$, n.s. $]$. The interaction of ability with lexicality was significant for the six-letter arrays $[F(1,17)=8.87, p<.01]$, but not for four-letter arrays $[F(1,17)=3.25$, n.s. $]$. Thus, ignoring the variable of spatial redundancy, the two groups of readers differ primarily in that: (1) less skilled readers are slower than highly skilled readers only in naming six-letter nonwords; (2) highly skilled readers show an arraysize effect only on nonwords; and (3) less skilled readers

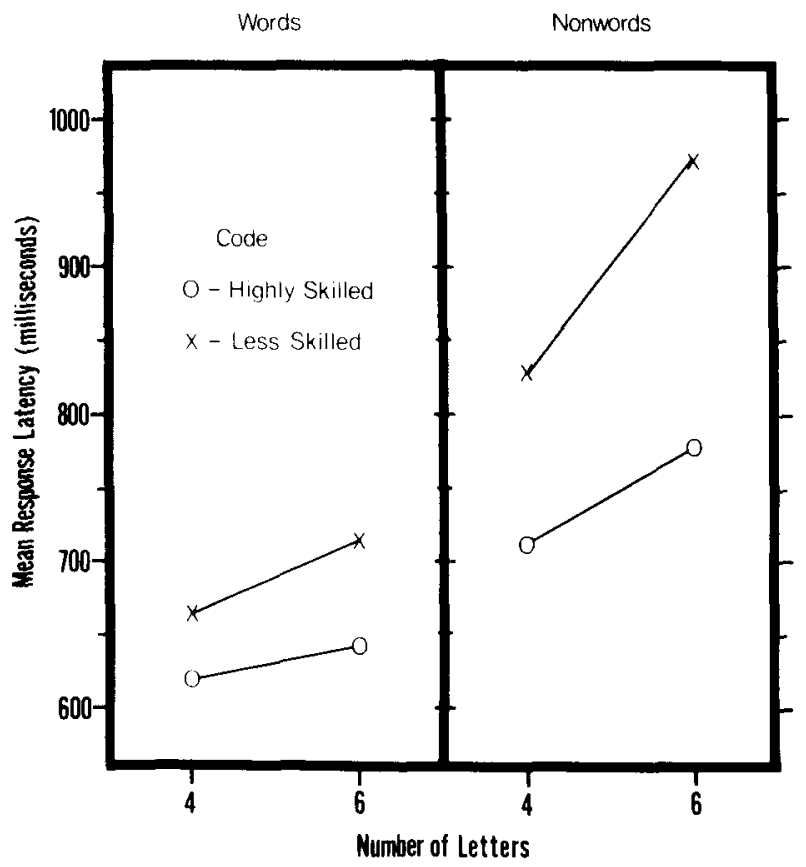

Figure 1. Mean vocalization latencies (collapsed over high and low spatial redundancy) for words and nonwords as a function of reading ability and array length.

show an array-size effect on both words and nonwords, with the effect being much greater on nonwords. The two groups of readers do not differ in naming times for high-frequency words.

The main effect of single-letter spatial redundancy as a structural variable was significant $[F(1,17)=34.58$, $p<.0001]$. High spatial redundancy strings were named more quickly than were low spatial redundancy strings. This effect, however, was limited to the nonword strings $[F(1,17)=40.78, p<.0001]$. The semantic variable far outweighs the structural variable for both reading ability groups in the vocalization latency task. This conclusion could, of course, be limited to the highfrequency words used as stimuli and to the fact that the low spatial redundancy words were low relative to the high words rather than being low in an absolute sense. Word frequency is a potent variable in the vocalization latency task. Perfetti and Hogaboam (1975), for example, found that good and poor fifth-grade readers did not differ in naming times for high-frequency words. The two groups differed significantly only on lowfrequency words. It is important to note that precautions were taken to insure that the low-frequency words were known to all the children and could be correctly pronounced by them. Thus, their finding that good and poor fifth-grade readers significantly differed only in naming times for low-frequency words cannot be attributed to differential vocabulary knowledge for the two groups.

The effect of spatial redundancy was greater for four-letter arrays than it was for six-letter arrays 


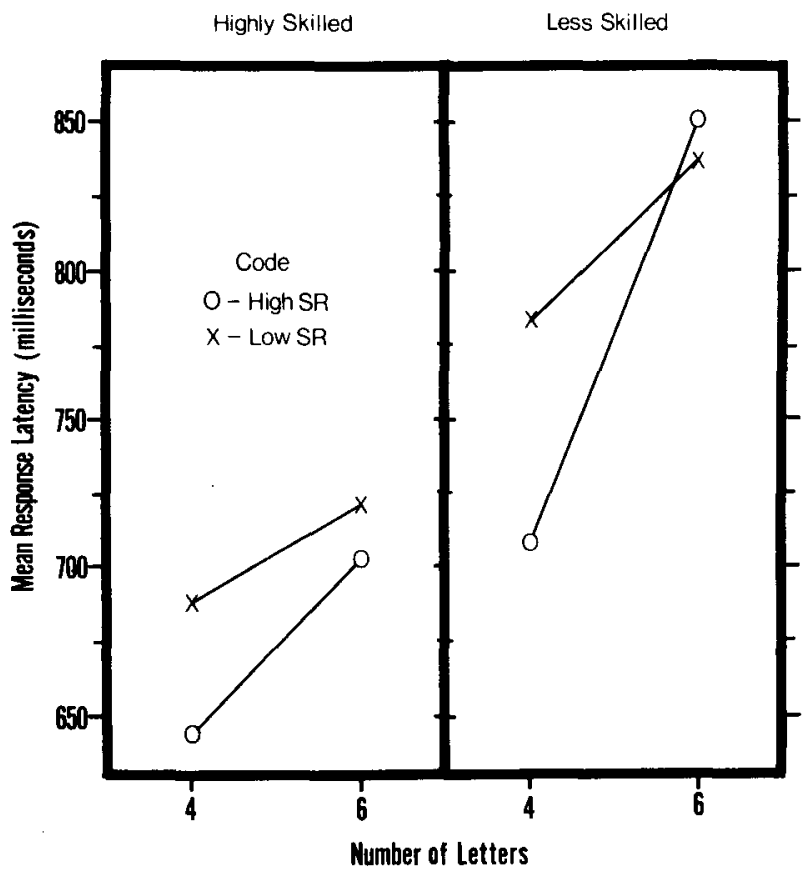

Figure 2. Mean vocalization latencies (collapsed over words and nonwords) for highly skilled and less skilled readers as a function of spatial redundancy and array length.

$[F(1,17)=24.69, \mathrm{p}<.0003]$. Reading ability interacted with spatial redundancy in the form of a three-way interaction of Ability by Array Length by Spatial Redundancy $[F(1,17)=8.17, \mathrm{p}<.01]$. This three-way interaction is shown in Figure 2. Simple-effects tests showed that the previously mentioned two-way interaction of spatial redundancy with array length was significant only for the less skilled readers $[F(1,17)=36.00, p<.001]$. Less skilled readers used spatial redundancy only on four-letter displays, whereas the differential use of redundancy as a function of array length was not significant for the highly skilled readers $[F(1,17)=2.90$, n.s. $]$. Of particular interest is the fact that ability did not interact with array length on low spatial redundancy displays $[F(1,17)<1]$. It was only on high spatial redundancy displays that a significant Ability by Array Length interaction occurred $[F(1,17)=17.00$, $\mathrm{p}<.001]$. As can be seen from Figure 2, highly skilled readers are no slower on six-letter high-redundancy displays than they are on four-letter low-redundancy displays, whereas less skilled readers always show a significant effect of adding two letters. Thus, it may be said that highly skilled readers use spatial redundancy to offset the effects of array length, whereas less skilled readers do not. However, since this effect is largely due to the nonwords, its relevance to the reading process is not readily apparent.

Syllable effects. If words are named by visual access of the lexicon, whereas nonwords are named by phonological recoding, differential effects of number of syllables on word- and nonword-naming times should be observed. There should be no effect of number of syllables for words, and, since number of syllables and number of phonemes are correlated, there should be a marked effect of number of syllables on nonwords. This is assuming that an abstract phonological representation of a visual nonword stimulus is formed prior to articulation.

In order to determine whether highly skilled and less skilled readers show differential effects of number of syllables, data from the six-letter word and nonword displays were analyzed as a function of whether they contained one or two syllables. An analysis of variance was then performed on the group means shown in Table 5. The results should be interpreted with caution, since the number of observations at each syllable length was unequal (14 one-syllable strings and 60 two-syllable strings). As was to be expected from the Reader Ability by Array Length interaction of the previous analysis, with only six-letter stimuli there was a main effect of reader ability $[F(1,17)=4.53, p<.05]$. The main effect of lexicality was significant $[F(1,17)=51.20$, $\mathrm{p}<.0001]$ and interacted with the reader ability factor $[F(1,17)=5.32, p<.05]$. Simple-effects tests showed that the two groups differed only on the nonwords. The main effect of number of syllables was significant $[F(1,17)=18.00, p<.001]$. However, the interaction of number of syllables with lexicality was highly significant $[F(1,17)=30.00, p<.0001]$. Simpleeffects tests showed that the time needed to obtain the names of words did not vary as a function of whether the words contained one or two syllables. Naming time for nonwords, however, was significantly influenced by whether the nonwords contained one or two syllables. The reader ability factor did not interact with the number of syllables factor $[F(1,17)=2.00$, n.s. $]$. Thus, it would again appear that neither highly skilled nor less skilled college readers retrieve the pronunciation of words by phonological recoding. When nonwords are to be named, phonological recoding is mandatory and syllable effects are obtained. There is no evidence from the present analysis for articulation taking place without the formation of a prior abstract phonological representation for either group of readers. These findings are in conflict with the Frederiksen and Kroll (1976) finding that naming time for both words and nonwords was not affected by number of syllables. Whereas the

Table 5

Mean Vocalization Latencies (in Milliseconds) for Six-Letter Words and Nonwords in Experiment 3 as a Function of Reading Ability and Number of Syllables

\begin{tabular}{cccccc}
\hline & \multicolumn{2}{c}{ Words } & & \multicolumn{2}{c}{ Nonwords } \\
\cline { 2 - 3 } \cline { 5 - 6 } $\begin{array}{c}\text { Reading } \\
\text { Group }\end{array}$ & $\begin{array}{c}\text { One } \\
\text { Syllable }\end{array}$ & $\begin{array}{c}\text { Two } \\
\text { Syllables }\end{array}$ & $\begin{array}{c}\text { One } \\
\text { Syllable }\end{array}$ & $\begin{array}{c}\text { Two } \\
\text { Syllables }\end{array}$ \\
\hline Highly Skilled & 637 & 646 & 723 & 790 \\
Less Skilled & 700 & 722 & & 870 & 991 \\
\hline
\end{tabular}


differences between the Frederiksen and Kroll study and the present study may be attributable to the reader ability subject variable, I am more inclined to reconcile the differences on the basis of procedural differences. As previously mentioned, the interpretation of reaction times obtained with brief stimulus presentations and high error rates is not straightforward.

Given the significant effect of number of syllables on six-letter nonwords, the possibility must be entertained that the larger effect of spatial redundancy for the four-letter stimuli may be due to number of syllables as well as to spatial redundancy. It will be recalled that spatial redundancy was confounded with number of syllables for the four-letter strings, but not for the sixletter strings. Of the 20 nonword low spatial redundancy four-letter strings, 11 had one syllable, 8 had two syllables, and 1 (udea) had three syllables. A mean was calculated for each subject over the 11 one-syllable four-letter nonword strings and the 8 two-syllable fourletter nonword strings. The group mean for the highly skilled readers was $737 \mathrm{msec}$ for one-syllable four-letter low nonwords and $753 \mathrm{msec}$ for two-syllable four-letter nonwords. For the less skilled readers, the group mean for one-syllable four-letter low nonwords was $851 \mathrm{msec}$ and, for two-syllable low nonwords, the mean was $903 \mathrm{msec}$. Number of syllables apparently accounts for some of the variability between four-letter highredundancy and four-letter low-redundancy nonwords. Nineteen of the 20 high-redundancy four-letter nonwords had one syllable. The means for the one-syllable high-redundancy nonwords was $691 \mathrm{msec}$ for the highly skilled readers and 797 msec for the less skilled readers, so, clearly, not all of the differences between the fourletter high- and low-redundancy nonwords can be attributed to number of syllables.

It would appear from the present experiment that visually presented words and nonwords are not decoded into sound in the same manner by either highly skilled or less skilled readers. The variables of array length, spatial redundancy, and number of syllables all exerted differential effects on words and nonwords. In conjunction with the regular vs. exception word variable results of Experiments 1 and 2, the results of Experiment 3 provide a strong argument against the phonemic recoding hypothesis for word recognition set forth by Rubenstein, Lewis, and Rubenstein (1971) for both highly skilled and less skilled mature readers. Instead, the results for both reading groups are congruent with the claim made by Forster and Chambers (1973) that visually presented words are named by a direct visual lexical access. Stored with each word in the lexicon is a program for pronouncing the word.

The main results of Experiment 3 may be summarized as follows: (1) High-frequency words are named by direct visual lexical access by both highly skilled and less skilled college readers; (2) less skilled readers show an effect of array length on words. whereas highly skilled readers do not; (3) highly skilled readers use spatial redundancy to offset the effect of array length on nonwords, whereas less skilled readers do not; and (4) reader ability differences do not show up in decoding highfrequency words, but they are marked on nonwords.

Whereas it is true that reading words and nonwords aloud has more face validity to the reading process than the simpler tasks used to investigate letter identification, the price paid for the greater face validity gained by using a more complex task is that it is difficult (if not impossible) to pinpoint the locus of the variables manipulated. In order to go from print to sound with either words or nonwords, a visual code must be formed. If the stimulus is a word, the name code can be retrieved from the lexicon. In the case of a nonword, the name code must be obtained by phonological recoding. With both words and nonwords, a motor-articulatory program must then be initiated. Since both groups of readers name words by retrieving the pronunciations from a visual access of the lexicon, the obtained differential effects of word length suggest reader ability differences in the formation of a visual code. It should also be noted that the average cost of two additional letters for the less skilled readers was roughly twice that of the highly skilled readers on both word and nonword displays. This too suggests basic reading ability differences in the formation of a visual code, a stage of processing common to both the word- and the nonwordnaming tasks. A strong case for highly skilled and less skilled mature readers differing primarily in the formation of a visual code could have been made if the two groups had been equivalent on low spatial redundancy words, differing only on high spatial redundancy words. This did not occur. Spatial redundancy differentiated the two groups only on the nonwords, where its effect could be due to the visual, the phonological, or the articulatory requirements of the naming task. The naming control task used in Experiment 2 should make it possible at least to eliminate the motor-articulatory component as the locus of the observed effects in Experiment 3. Also, the way the stimuli were constructed for Experiment 3, the words and nonwords within any one level of string length and spatial redundancy were closely equated for initial phonemic structure. Comparisons across levels of string length and spatial redundancy, however, are (of necessity) confounded with initial phonemic structure. The naming control condition will also make it possible to evaluate whether the observed effects in Experiment 3 may have been due to initial phonemic structure in the sense that this variable may influence the time needed to merely trigger the voice-relay key.

\section{EXPERIMENT 4}

\section{Method}

Experiment 4 is a complete replication of Experiment 3 , with the exception that each word and nonword remained in view for $2 \mathrm{sec}$ before a light appeared that signaled the subject to initiate pronunciation. An additional 10 highly skilled and 10 
Table 6

Naming Control Latencies (in Milliseconds) for Words and Nonwords as a Function of Reading Ability, Spatial Redundancy, and Array length

\begin{tabular}{lcccccc}
\hline \multirow{2}{*}{$\begin{array}{c}\text { Spatial } \\
\text { Redun- } \\
\text { dancy }\end{array}$} & $\begin{array}{c}\text { Four } \\
\text { Letters }\end{array}$ & $\begin{array}{c}\text { Six } \\
\text { Letters }\end{array}$ & Mean & \multicolumn{4}{c}{$\begin{array}{c}\text { Four } \\
\text { Letters }\end{array}$} & $\begin{array}{c}\text { Six } \\
\text { Letters }\end{array}$ & Mean \\
\hline & \multicolumn{4}{c}{ Highly Skilled Reading Group } \\
HIgh & 391 & 406 & 398 & 401 & 415 & 408 \\
Low & 403 & 390 & 396 & 400 & 409 & 405 \\
Mean & 397 & 398 & 397 & 400 & 412 & 406 \\
& & Less & Skilled & Reading Group & \\
High & 353 & 368 & 360 & 381 & 408 & 394 \\
Low & 360 & 356 & 358 & 375 & 391 & 383 \\
Mean & 357 & 362 & 359 & 378 & 399 & 389 \\
\hline
\end{tabular}

less skilled readers served as subjects, with the same criteria previously used for subject selection. The stimuli and apparatus were the same used in Experiment 3. The only procedural change was that each word and nonword remained in view for $2 \mathrm{sec}$ prior to the appearance of the signal light. Time for response was measured from the appearance of the light on the screen to the time when the voice-relay key was triggered.

\section{Results and Discussion}

Given $2 \mathrm{sec}$ for visual and name code formation, the effect of reader ability did not approach significance either as a main effect or in any interaction. As can be seen from Table 6, the less skilled readers were actually somewhat faster than the highly skilled readers, although the difference did not approach significance $[\mathrm{F}(1,18)<1]$.

The analysis of variance performed on the group means shown in Table 6 revealed a significant interaction of Lexicality by Number of Letters $[F(1,18)=7.11$, $p<.015]$. Simple-effects tests showed no difference between words and nonwords with four letters, but six-letter nonwords were slower than six-letter words $[F(1,18)=19.60, p<.001]$. This might be due to the greater incidence of voiced consonants in the initial position of six-letter words than in the six-letter nonwords (13 vs. 10). Response latencies for six-letter words were not significantly longer than for four-letter words, while the corresponding nonword conditions did show a significant effect of array length $[F(1,18)=14.31$, $\mathrm{p}<.001]$.

There was also a significant interaction of spatial redundancy with number of letters $[F(1,18)=10.74$, $\mathrm{p}<.0044]$. Simple-effects tests showed no differences due to spatial redundancy in the four-letter condition. The 13-msec advantage for six-letter low spatial redundancy strings over six-letter high spatial redundancy strings was significant $[F(1,18)=12.33, p<.005]$. Thus, the advantage of spatial redundancy is not in the motor-articulatory components of the vocalization latency task. With six-letter strings, the consonant letters $b, c, f, p$, and $w$ are all most redundant in the initial position. Of these five consonants, only two are voiced.
The effect of array length was only significant in the high spatial redundancy condition $[F(1,18)=18.49$, $\mathrm{p}<.001]$. This is probably due in part to the greater initial phonemic complexity of some of the six-letter high spatial redundancy strings over four-letter high spatial redundancy strings. All four-letter high spatial redundancy strings began with a consonant followed by a vowel. Of the 40 four-letter high spatial redundancy strings, 17 began with a voiced consonant. Of the 40 six-letter high spatial redundancy strings, 34 began with a simple consonant-vowel pattern and 6 with a consonant cluster. Of the $34 \mathrm{CV}$ strings, 9 began with a voiced consonant.

Apparently, there are differences in the time required to trigger the voice relay as a function of both initial phonemic structure and voicing. The observed differences due to spatial redundancy in the naming control condition, however, work against the hypothesis that high spatial redundancy facilitates performance, with high spatial redundancy six-letter strings taking longer to trigger the voice-relay key than low spatial redundancy six-letter strings. ${ }^{4}$

Adjusted means were calculated for each subject in the vocalization latency task of Experiment 3 by subtracting out the Experiment 4 naming control means shown in Table 6. An analysis of variance was then performed on the adjusted means shown in Table 7. In contrast to the analysis of variance performed on the overall vocalization latencies, a significant main effect of reader ability emerged $[\mathrm{F}(1,17)=6.01, \mathrm{p}<.0253]$. The effect of array length was highly significant $[F(1,17)=43.40, p<.0001]$, as was its interaction with reader ability $[F(1,17)=5.84, p<.0272]$. Again, less skilled readers are more disadvantaged than highly skilled readers by the addition of two letters. The main effect of lexicality was significant $[F(1,17)=48.66$, $p<.0001]$. In contrast to the analysis of the unadjusted vocalization latencies, lexicality did not significantly

Table 7

Adjusted Mean Vocalization Latencies (in Milliseconds) for Words and Nonwords in Experiment 3 as a

Function of Reading Ability, Spatial Redundancy, and Array Length

\begin{tabular}{|c|c|c|c|c|c|c|}
\hline \multirow{2}{*}{$\begin{array}{l}\text { Spatial } \\
\text { Redun- } \\
\text { dancy }\end{array}$} & \multicolumn{3}{|c|}{ Words } & \multicolumn{3}{|c|}{ Nonwords } \\
\hline & $\begin{array}{c}\text { Four } \\
\text { Letters }\end{array}$ & $\begin{array}{c}\text { Six } \\
\text { Letters }\end{array}$ & Mean & $\begin{array}{l}\text { Four } \\
\text { Letters }\end{array}$ & $\begin{array}{c}\text { Six } \\
\text { Letters }\end{array}$ & Mean \\
\hline & \multicolumn{6}{|c|}{ Highly Skilled Reading Group } \\
\hline $\begin{array}{l}\text { High } \\
\text { Low }\end{array}$ & $\begin{array}{l}224 \\
222\end{array}$ & $\begin{array}{l}246 \\
249\end{array}$ & $\begin{array}{l}235 \\
235\end{array}$ & $\begin{array}{l}273 \\
350\end{array}$ & $\begin{array}{l}340 \\
395\end{array}$ & $\begin{array}{l}306 \\
372\end{array}$ \\
\hline \multirow[t]{2}{*}{ Mean } & 223 & 247 & 235 & 311 & 367 & 339 \\
\hline & \multicolumn{6}{|c|}{ Less Skilled Reading Group } \\
\hline $\begin{array}{l}\text { High } \\
\text { Low }\end{array}$ & $\begin{array}{l}301 \\
312\end{array}$ & $\begin{array}{l}364 \\
343\end{array}$ & $\begin{array}{l}332 \\
327\end{array}$ & $\begin{array}{l}381 \\
519\end{array}$ & $\begin{array}{l}562 \\
584\end{array}$ & $\begin{array}{l}471 \\
551\end{array}$ \\
\hline Mean & 306 & 353 & 329 & 450 & 573 & 511 \\
\hline
\end{tabular}

Note-Naming control latencies obtained in Experiment 4 were subtracted from the original vocalization latencies. 
interact with reader ability $[F(1,17)=3.59, p<.07]$. Apparently, some of the less skilled readers' difficulty with nonwords can be attributed to uncertainty about how to pronounce nonwords after the phonological recoding has taken place.

The main effect of spatial redundancy was again significant $[F(1,17)=46.27, p<.0001]$, as was its interaction with number of letters $[\mathrm{F}(1,17)=12.63$, $\mathrm{p}<.0024]$. As in the analysis of unadjusted vocalization latencies, reader ability interacted with spatial redundancy in the form of a three-way interaction of Ability by Number of Letters by Spatial Redundancy $[F(1,17)=8.55, \quad p<.0095]$. Simple-effects tests performed on the three-way interaction showed that the Number of Letters by Spatial Redundancy interaction was not significant for the highly skilled readers $[F(1,17)<1]$, but was highly significant for the less skilled readers $[F(1,17)=20.88, p<.001]$. Again, highly skilled readers are no slower on six-letter highredundancy strings than they are on four-letter lowredundancy strings, whereas the less skilled readers always show a significant effect of two additional letters. As in the previous analysis, spatial redundancy was effective only with the nonwords $[F(1,17)=46.83$, $p<.0001]$. The role of word frequency in word recognition, unconfounded with vocabulary knowledge and production effects, would appear to be a fruitful area for further investigation.

The present experiments point to the importance of the visual components of the word decoding task and serve to focus attention on other forms of orthographic regularity present in words that can affect the rate at which letters are recognized. Spatial redundancy is only one of these potential variables. Skilled readers may differ from less skilled readers in being able to make more use of one or more forms of orthographic regularity present in words to process individual letters in parallel extremely rapidly. Clearly, more research is needed on visual code formation as a function of variables subsumed under the rubric of orthographic regularity in conjunction with reading ability.

\section{GENERAL DISCUSSION}

It would appear that reading comprehension cannot be divorced from rapid and accurate word recognition, even in adults with a great deal of reading practice. Less skilled college readers are slower than highly skilled college readers in decoding all but short highfrequency words. Whereas this result may not be particularly surprising, it was not a foregone conclusion. One implication of this finding is that an understanding of the processes involved in word recognition cannot be considered trivial to a fuller understanding of the reading process itself. This is not to say that highly skilled and less skilled readers, at any grade level, differ only in word recognition processes, but rather that this locus of difficulty is important enough to necessitate elucidation.

Since phonological recoding takes time, one of the original hypotheses was simply that the degree of phonological recoding in highly practiced readers would be inversely related to reading ability. The probably simple-minded notion was that highly skilled readers might go directly from print to meaning to sound in the simple tasks used, whereas less skilled readers might go from print to sound via phonological recoding. The combined results from the present experiments are unequivocal in demonstrating that neither group of adult readers derive the name code of a word by phonological recoding. Both highly skilled and less skilled readers retrieve the pronunciation of words from the lexicon. Nonword performance indicated that less skilled readers, when forced to derive a name by phonological encoding, are at more of a disadvantage than are highly skilled readers.

Given the empirical observation that decoding skills are related to reading comprehension, how can we account for the relationship? If the meanings of printed words were obtained by going through the speech system, the explanation would be obvious. However, the relationship between decoding skills and reading comprehension is not that simple, even in young children. Golinkoff and Rosinski (1976), for example, found weaker decoding skills in third-and fifth-grade children who were poor readers. Yet they also found that none of the children obtained the meaning of words by decoding printed words into their sounds. Word meanings are accessed visually even by poor readers in the third grade. It may be that good decoding skills are an epiphenomenon of skilled reading. I suspect that the nonword decoding task differentiates skilled and less skilled readers because it provides a measure of linguistic awareness that, in turn, determines the ease with which the reading process is acquired in young readers and the ease with which reading was acquired in adult readers. The major advantage of an alphabetic writing system is that the child who is learning to read will be able to recognize words that are in his spoken vocabulary when he first encounters them in print. However, it is only in the beginning years that the oral vocabulary outstrips the written vocabulary. It seems to me that, even as children, we initially encounter the truly rich and interesting words of a language in print, rather than in oral communication. As we get older, it seems even more unlikely that unfamiliar words encountered in print will be part of our oral vocabulary. We obtain the meaning of a novel word encountered in print by using context rather than by decoding into sound. If context fails, there is always the dictionary. From this point of view, the major advantage of an alphabetic writing system is at the initial learning-toread stage, where it serves as a powerful reinforcer if the child can grasp the alphabetic principle. The difficulty that arises with a writing system that makes reading 
at least initially parasitic upon speech is that it is very abstract and requires a fairly high degree of linguistic awareness. The child who has difficulty segmenting speech sounds into units smaller than the syllable will not be able to learn to read easily (see Liberman, Shankweiler, Liberman, Fowler, \& Fischer, 1977). It may be that highly skilled adult readers learned to read by making full use of the alphabetic principle. With increased reading practice, however, printed representations of words can be treated as visual symbols from which meaning can be directly obtained. From this point of view, highly skilled adult readers go from print to sound using a visual access simply because it is the most efficient way to proceed. Less skilled adult readers, on the other hand, may go from print to sound using a visual access, not because the visual route is fast, but because the phonological route is too slow. Word decoding differences, since they involve word recognition, are directly relevant to reading comprehension because they speak to the speed with which meaning is obtained visually. Clearly, we need to know more about the formation of visual codes as a function of reading ability.

Reading with an alphabetic writing system is both a language-based skill (at least initially) and a highly unnatural visual skill. Mild difficulties in visual perception that may not interfere with most other tasks may well cause serious problems in reading. Bearing in mind that spatial redundancy is based on the encoding of order information, one such difficulty may be in the perception of order relations within a string of letters. There is evidence (Corkin, 1974; Mason, Katz, \& Wicklund, 1975; Mason, Note 2) to support the notion that at least some less skilled younger readers are deficient in the processing of order information (where is it?), rather than in the processing of item information (what is it?). It should be noted, in this connection, that another consequence of an alphabetic writing system is that it is uneconomical in terms of the amount of material needed to convey information. As Kolers (1970) points out, the general rule with writing systems is that the fewer the elements the user must carry in memory, the greater will be the spatial extent of the message symbolized, and vice versa. Thus, speed of visual processing becomes very important with an alphabetic system because of the demands it places upon short-term memory.

Since college students have been the most frequently used subject population in studies investigating the formation of visual and name codes, one important implication of the present investigation is that the subject variable of reading ability cannot be overlooked simply because we are working with the college population. The obtained main effects and interactions of reading ability with other variables in the present studies speak to the lack of homogeneity of reading ability within the college population. From time to time, individual differences are reported in experiments. For example, Manelis (1974) reported a bimodal distribution of subjects in research investigating the effect of meaningfulness in tachistoscopic letter identification. One group of subjects identified letters in words more accurately than letters in nonwords, whereas another group of subjects showed a negative meaningfulness effect. While such differences may indeed be due to subjects' strategies or to differences in the tendency to access lexical memory, a natural question at this point is just how much in the way of individual differences that have been reported in experiments may be due to the subject variable of reading ability.

\section{REFERENCE NOTES}

1. Frederiksen, J. R. Decoding skills and lexical retrieval. Paper presented at the Psychonomic Society meeting, St. Lou is, 1976.

2. Mason, M. Perception of the order of letters and nonsense forms in fifth-grade children as a function of reader ability. Unpublished manuscript, 1975. (Available from M. Mason, lowa State University, Ames, Iowa 50011.)

\section{REFERENCES}

Baron, J., \& Strawson, C. Use of orthographic and wordspecific knowledge in reading words aloud. Journal of Experimental Psychology: Human Perception and Performance, 1976, 2, 386-393.

Baron, J., \& Thurston, I. An analysis of the word-superiority effect. Cognitive Psychology, 1973, 4, 207-228.

Coltheart, M. Lexical access in simple reading tasks. In G. Underwood (Ed.), Strategies of information processing. New York: Academic Press, in press.

Corkin, S. Serial-ordering deficits in inferior readers. Neuropsychologia, 1974, 12, 347-354.

Forster, K. I., \& Chambers, S. M. Lexical access and naming time. Journal of Verbal Learning and Verbal Behavior, 1973, 12, 627-635.

Frederiksen, J. R., \& Kroll, J. F. Spelling to sound: Approaches to the internal lexicon. Journal of Experiment Psychology: Human Perception and Performance, 1976. 2. 361-379.

Gol.inkoff, R. M., \& RosınskI, R. R. Decoding, semantic processing and reading comprehension skill. Child Development, 1976, 47, 252-258.

GrofF, P. Research in brief: Shapes as cues to word recognition. Visible Language, 1975, 9, 67-71.

Kolers, P. A. Three stages of reading. In H. Levin \& J. P. Williams (Eds.), Basic studies on reading. New York: Basic Books, 1970.

Liberman, I. Y., Shankweiler, D., Liberman, A. M., Fowler, C., \& Fischer, F. W. Phonetic segmentation and recoding in the beginning reader. In A. S. Reber \& D. L. Scarborough (Eds.), Toward a psychology of reading. The proceedings of the CUNY Conference. New York: John Wiley, 1977.

MAKITA, K. Rarity of reading disability in Japanese children. American Journal of Orthopsychiatry, 1968, 38, 599-614.

MANELIS. L. The effect of meaningfulness on tachistoscopic word perception. Perception \& Psychophysics. 1974, 16, 182-192.

Mason, M. Reading ability and letter search time: Effects of orthographic structure defined by single-letter positional frequency. Journal of Experimental Psychology: General, 1975, 104, 146-166. 
Mason, M. The role of spatial redundancy in grapheme recognition: Perception or inference? Journal of Experimental Psychology: Human Perception and Performance, in press.

Mason, M., \& KATZ, L. Visual processing of nonlinguistic strings: Redundancy effects and reading ability. Journal of Experimental Psychology: General, 1976, 105, 338-348.

Mason, M., Katz, L., \& Wickiund, D. A. Immediate spatial order memory and item memory in sixth-grade children as a function of reader ability. Journal of Educational Psychology, 1975, 67, 610-616.

Massaro, D. W., Venezky, R. L., \& Taylor, G. A. Orthographic regularity, positional frequency, and visual processing of letter strings. Journal of Experimental Psychology: General, in press.

Mattingly, I. G. Reading, the linguistic process, and linguistic awareness. In J. F. Kavanaugh \& I. G. Mattingly (Eds.), Language by ear and by eye. Cambridge, Mass: MIT Press, 1972.

Mayzner, M. S., \& Tresselt, M. E. Tables of single-letter and diagram frequency counts for various word-length and letter-position combinations. Psychonomic Monograph Supplements, 1965, 1(Whole No. 2), 13-32.

McClelland, J. L. Preliminary letter identification in the perception of words and nonwords. Journal of Experimental Psychology: Human Perception and Performance, 1976, 2 , 80-91.

MCClelland, J. L., \& Johnston, J. C. The role of familiar units in the perception of words and nonwords. Perception \& Psychophysics, 1977, 22, 249-261.

Pachella, R. G. The interpretation of reaction time in information-processing research. In B. H. Kantowitz (Ed.), Human information processing: Tutorials in performance and cognition. New York: John Wiley, 1974.

Perfetti, C. A., \& Hogaboam, T. Relationship between single word decoding and reading comprehension skill. Journal of Educational Psychology, 1975, 67, 461-469.

Rozin, P., \& Gleitman, L. R. The structure and acquisition of readingII: The reading process and the acquisition of the alphabetic principle. In A. S. Reber \& D. L. Scarborough (Eds.), Toward a psychology of reading: The proceedings of the CUNY conference. New York: John Wiley, 1977.
Rozin, P., Poritsky, S., \& Sotsby, R. American children with reading problems can easily learn to read English represented by Chinese characters. Science, 1971, 171, 1264-1267.

Rubenstein, H., Lewis, S. S., \& Rubenstein, M. A. Evidence for phonemic recoding in visual word recognition. Journal of Verbal Learning and Verbal Behavior, 1971, 10, 645-657.

SMtTh, E. E., \& SpoenR, K. T. The perception of printed English: A theoretical perspective. In B. H. Kantowitz (Ed.), Human information processing: Tutorials in performance and cognition. New York: John Wiley, 1974.

SмIтH, F. Understanding reading. New York: Holt, Rinehart, \& Winston. 1971.

THORNDIKE, E. L., \& LORGE, I. The teacher's word book of 30.000 words. New York: Teacher's College, Columbia University Press, 1944.

VENEZKY, R. L. The structure of English orthography. The Hague: Mouton, 1970.

\section{NOTES}

1. Analysis of the data with "sword" eliminated completely vitiated the higher error rate for exception words. All other significant effects remained unchanged.

2. The author would like to thank the English department, particularly Dale Ross and William Fowler, for making it possible for our research staff to administer the test during class periods.

3. The word and nonword stimuli were treated as fixed effects in the analysis. With the constraints of no letter repeats, high frequency of occurrence, and clear separations along the dimension of single-letter spatial redundancy, neither the words nor their pronounceable nonword derivations could be regarded as having been randomly selected.

4. The same comparisons for syllable effects made in Experiment 3 yielded no differential effects of number of syllables in the naming control condition.

(Received for publication June 16, 1978; revision accepted August 21, 1978.) 